\title{
Food Outlets Dietary Risk (FODR) assessment tool: study protocol for assessing the public health nutrition risks of community food environments
}

Claire Elizabeth Pulker ${ }^{1,2^{*}}$ (D, Georgina S. A. Trapp ${ }^{3,4}$, Mark Fallows ${ }^{5}$, Paula Hooper ${ }^{4}$, Heather McKee ${ }^{3}$ and Christina Mary Pollard ${ }^{1,2}$

\begin{abstract}
Background: Availability and accessibility of nutritious foods can vary according to the food outlets present within a neighbourhood or community. There is increasing evidence that community food environments influence food choice, diet and the risk of diet-related chronic disease, however contemporary community food environments assessments (e.g. unhealthy fast food outlets versus healthy supermarkets or fruit and vegetable shops) may be too simplistic to accurately summarise the complexities of their impacts on food choice. This study protocol describes the development of the Food Outlets Dietary Risk (FODR) assessment tool for use by local government in Perth, Western Australia.

Methods: Similar to food safety risk assessment, the FODR assessment tool rates the potential harmful public health nutrition impact of food outlets by identifying and characterising the issues, and assessing the risk of exposure. Scores are attributed to six public health nutrition attributes: 1) availability of nutrient-poor foods; 2) availability of nutritious foods; 3) acceptability and appeal; 4) accessibility; 5) type of business operation; and 6) complex food outlet considerations. Food retail outlets are then classified as having a low, medium, high or very high dietary risk based on their total score.

(Continued on next page)
\end{abstract}

\footnotetext{
* Correspondence: c.pulker@curtin.edu.au

'School of Public Health, Curtin University, Kent Street, GPO Box U1987, Perth, Western Australia 6845, Australia

${ }^{2}$ East Metropolitan Health Service, Kirkman House, 20 Murray Street, East Perth, Perth, Western Australia 6004, Australia

Full list of author information is available at the end of the article
}

(c) The Author(s). 2020 Open Access This article is licensed under a Creative Commons Attribution 4.0 International License, which permits use, sharing, adaptation, distribution and reproduction in any medium or format, as long as you give appropriate credit to the original author(s) and the source, provide a link to the Creative Commons licence, and indicate if changes were made. The images or other third party material in this article are included in the article's Creative Commons licence, unless indicated otherwise in a credit line to the material. If material is not included in the article's Creative Commons licence and your intended use is not permitted by statutory regulation or exceeds the permitted use, you will need to obtain permission directly from the copyright holder. To view a copy of this licence, visit http://creativecommons.org/licenses/by/4.0/. The Creative Commons Public Domain Dedication waiver (http://creativecommons.org/publicdomain/zero/1.0/) applies to the data made available in this article, unless otherwise stated in a credit line to the data. 


\begin{abstract}
(Continued from previous page)
Discussion: A local government administered tool to rate the public health nutrition risk of food outlets requires data which can be collected during routine assessments or sourced from the internet. The ongoing categorical classification of foods available within food outlets as either unhealthy or nutritious will require nutrition scientists' input. An objective risk assessment of the dietary impact of food retail outlets can guide local government planning, policies and interventions to create supportive community food environments. It is intended that locally relevant data can be sourced throughout Australia and in other countries to apply the local context to the FODR assessment tool. Utility and acceptability of the tool will be tested, and consultation with environmental health officers and public health practitioners will inform future iterations.
\end{abstract}

Keywords: Community food environments, Food outlet, Food retail, Supermarket, Fast food outlet, Local government, Risk assessment, Diet

\section{Background}

There is increasing evidence that food environments influence food choices and diet, therefore improving food environments to reduce the risk of diet-related chronic disease is a public health priority [1-3]. The availability and accessibility of healthy food is an important contributor to healthy diets [4], and varies according to the food outlets present within a neighbourhood or community [3]. The ability of community food (or nutrition) environments to support healthy eating can be measured by identifying the number, type, location and accessibility of food outlets within a specified area [5]. Governments, non-government health organisations and researchers increasingly use food outlet listings to attempt to assess the relative healthfulness of community food environments [6]. Two commonly used measures are proximity to food outlets, and total count or density of food outlets within a neighbourhood [7].

To date, community food environments assessment has mainly focused on identifying and mapping a limited number of food outlet types using supermarkets or greengrocers as a proxy for healthy food access, and fast food or takeaway outlets as a proxy for unhealthy food access $[8,9]$. For example, the United States (US) Center for Disease Control and Prevention's modified Retail Food Environment Index (mRFEI) is a ratio of outlets considered to be healthy (supermarkets, large grocery stores, supercentres, and greengrocers) to outlets considered to be less healthy (fast food, small grocery stores, and convenience stores) [10]. Whilst there is increasing evidence that food environments contribute to food choices and diet $[1,2]$, evidence of an association between community food environments and diet related non-communicable diseases is inconsistent [11, 12]. Existing classification and measurement approaches may be too simplistic to accurately summarise the complexities of food outlet impacts on food choice [13].

The role supermarkets play within community food environments is unclear [9]. Australian supermarkets and grocery stores are an important source of healthy foods but they are also the main retailer of unhealthy (discretionary) foods that government dietary advice recommends to limit consumption of [14]. For example, in Australia $57 \%$ of total soft drinks sales and $48 \%$ of total snack foods sales were from supermarkets in 2017 [15]; and less than half of supermarket packaged foods are classified as healthy [16]. Most Australian supermarket checkouts display soft drinks and unhealthy snack foods including crisps, chocolate, and confectionery [17-19] and $74 \%$ of Australians purchase alcohol from a supermarket or stand-alone store owned by a supermarket group [20]. Shopping primarily at supermarkets was not associated with a better nutrient profile of packaged foods purchased in the US [21]; and in fact, despite supermarkets being the main retailer of food for the population (ensuring food security), few positive public health impacts of Australian supermarkets have been identified [22].

Some anomalies also exist in fast food outlets and takeaways. Studies conducted in the United States (US) and United Kingdom (UK) indicate fast food is energydense and nutrient-poor compared to home prepared food [23, 24], and there is an association between growth in fast food consumption and obesity in Australia [25]. Burgers are the main products sold at Australian fast food outlets (31\%), followed by pizza (27\%), and chicken-based fast food (18\%) [26]. Australian fast food or takeaway outlets can also provide healthful options such as fresh salad, wholemeal or wholegrain bread, dishes with a high proportion of vegetables, dishes that are not deep-fried, and fresh fruit [27, 28]. Therefore, a more nuanced system to rate the risk of food outlets to public health nutrition is needed to assist with understanding and potentially modifying the impact of community food environments on population diets.

Two Australian studies which developed detailed classifications of healthy and unhealthy food outlets have recognised these limitations $[8,29]$. Thornton and Kavanagh (2012) assigned ratings from +10 (most healthy) to - 10 (least healthy) to 20 types of food outlets, based on 
consultation with eight Australian and international academic researchers [8]. The participants were selected on the basis of conducting food environments research, and were asked to consider four factors when assigning their scores. Moayyed et al. (2017) also sought expert opinion from 26 Australian public health researchers and practitioners on the relative healthfulness of 24 food outlet types using a Delphi survey to rate the outlets from +10 (most healthy) to - 10 (least healthy) [29]. The participants were given a proposed set of scores for the outlets to comment on in two rounds of surveys; however, it is unclear how the proposed scores were derived or the factors considered by participants when making comments. In summary, the criteria that informed the ratings attributed in these studies were not transparent or consistent.

The commonly used risk assessment approach, adopted by the Codex Alimentarius system of international food standards [30, 31] comprises science-based identification, characterisation and analysis of issues, to estimate the likelihood and severity of an adverse health event occurring [32] may be a useful approach. Australia's Food Standards Australian New Zealand (FSANZ) applies a risk analysis approach which includes risk assessment, risk management and risk communication [32]. FSANZ has predominantly focussed on food safety as the priority to protect public health and safety; however the risk analysis approach could also be used to improve public health nutrition [33]. In Western Australia (WA), the Department of Health works in partnership with local government agencies (LGAs) to protect environmental health with a particular focus on food safety. The State government's Department of Health oversees the food regulatory system while LGAs are responsible for monitoring food standards within their district [34]. LGAs routinely assess food businesses as part of their food safety surveillance system but the relative healthfulness of the foods sold and potential impact on diet and health does not form part of this assessment. WA LGAs also have statutory responsibility for protecting community health and wellbeing in accordance with the Public Health Act 2016 [35]. Public health plans describing the strategies to be implemented to meet community public health needs are required from each LGA, which includes creating and maintaining healthy environments [35]. The risk assessment approach routinely used by LGAs for food safety could also be applied to public health nutrition risk to identify the relative healthfulness of food outlets and their potential impact on diet related non-communicable diseases. A tool to assist LGAs to rate the potentially harmful public health nutrition impact of food outlets is therefore needed.

\section{Methods/design}

\section{Study aim}

The aim of this protocol is to describe development of the Food Outlet Dietary Risk (FODR) assessment tool which incorporates public health nutrition issues. The FODR assessment tool is intended to be used to rate the potentially harmful public health nutrition impact of individual food outlets (i.e. food businesses with a consumer-facing retail or food service component), to inform surveillance and planning.

Public health nutrition includes the determinants of health that relate to a safe, nutritious, affordable, accessible, secure and environmentally sustainable food system [36]. Environmental sustainability is outside of the scope of this protocol because there are no recommendations or measures for environmental sustainability of the Australian population diet.

The risk assessment principles applied to the protocol include: using the best available evidence, recognising the inherent uncertainty in risk assessment, and using an iterative process [32].

\section{Setting}

The WA Department of Health delivers health services to the Perth metropolitan population via three area health services, including East Metropolitan Health Service (EMHS). EMHS provides tertiary, secondary, specialist, and community health care services that aim to maintain and improve the health of one-third of the WA population [37]. Thirteen LGAs are located within the EMHS geographic area, and they provide the setting for the current research.

\section{Study design}

The Standard Protocol Items: Recommendations for Interventions Trials (SPIRIT) checklist was used to guide this protocol (Supplementary Table 1) [38].

\section{Compilation of a database of food businesses}

LGAs are responsible for registering food businesses in WA. EMHS staff contacted the environmental health team at each of the 13 LGAs in April 2018 to request a list of registered food businesses within their area. A formal letter was followed up by telephone calls to address any questions concerning use of the data, and all data were provided by June 2018. A database of 6963 registered food businesses present in the EMHS area was constructed, which included 4136 food outlets, i.e. businesses with a food service or food retail component which sells foods to consumers.

\section{Classification of all food businesses}

A classification framework that identifies consumerfacing food retail (e.g. supermarkets, greengrocers) and food service outlets (e.g. cafes, takeaways), food preparation businesses (e.g. food manufacturers, wholesalers), charitable food provision (e.g. food pantries), and institutional food (e.g. school canteens, hospitals) was 
developed (Supplementary Table 2). Food outlets identified as consumer-facing are the focus of this study.

\section{Risk assessment of food businesses}

The WA Department of Health provides guidance to LGAs on risk assessment of food safety, including a tool which rates the following: food type and intended consumer use, activity of the food business, method of processing, size of customer base, and implementation of a food safety programme [34]. To assist with translation, the FODR assessment tool replicated this approach. Part A of the tool duplicates the existing WA Department of Health guidance for assessing food safety risk; part B incorporates dietary risk assessment (Fig. 1).

\section{Public health nutrition issue identification and characterisation}

The public health nutrition issue being addressed is diet quality consistent with the Australian Dietary Guidelines and Australian Guide to Healthy Eating recommendations [39]. Characterisation of the issue was informed by the recommendations made in three of the Australian Dietary Guidelines [40]. Guideline one states "To achieve and maintain a healthy weight, be physically active and choose amounts of nutritious food and drinks to meet your energy needs"; guideline two recommends eating a wide variety of foods from the nutritious five food groups every day as well as drinking water; and guideline three refers to limiting intake of discretionary foods that contain saturated fat, added salt, added sugars and alcohol [40]. Few Australians meet the nutritious five food group recommendations, only $8 \%$ of adults ate the recommended amount of vegetables and $5 \%$ met recommendations for both fruit and vegetables in 2017-18 [41]. The 2011 National Nutrition Survey found that only $10 \%$ of Australians ate enough dairy foods and alternatives; $14 \%$ ate enough lean meats and alternatives; and $30 \%$ ate enough cereal (grain) foods [42]. Nutrient-poor discretionary foods accounted for $35 \%$ of total dietary energy intake [42]. In terms of health risk, poor quality dietary patterns are responsible for one in five preventable deaths globally [43]. The typically poor quality Australian diet has contributed to an increased prevalence of noncommunicable diseases [41]. Almost half of Australians have at least one chronic disease, and the proportion of Australian adults classified as overweight or obese increased from $63 \%$ in $2014-15$ to $67 \%$ in 2017-18 [41].

Substantial changes in dietary patterns are needed at a population level to meet the recommendations of the Australian Dietary Guidelines and reduce dietary risk. The FODR assessment tool therefore assesses the risk associated with the availability of discretionary foods,

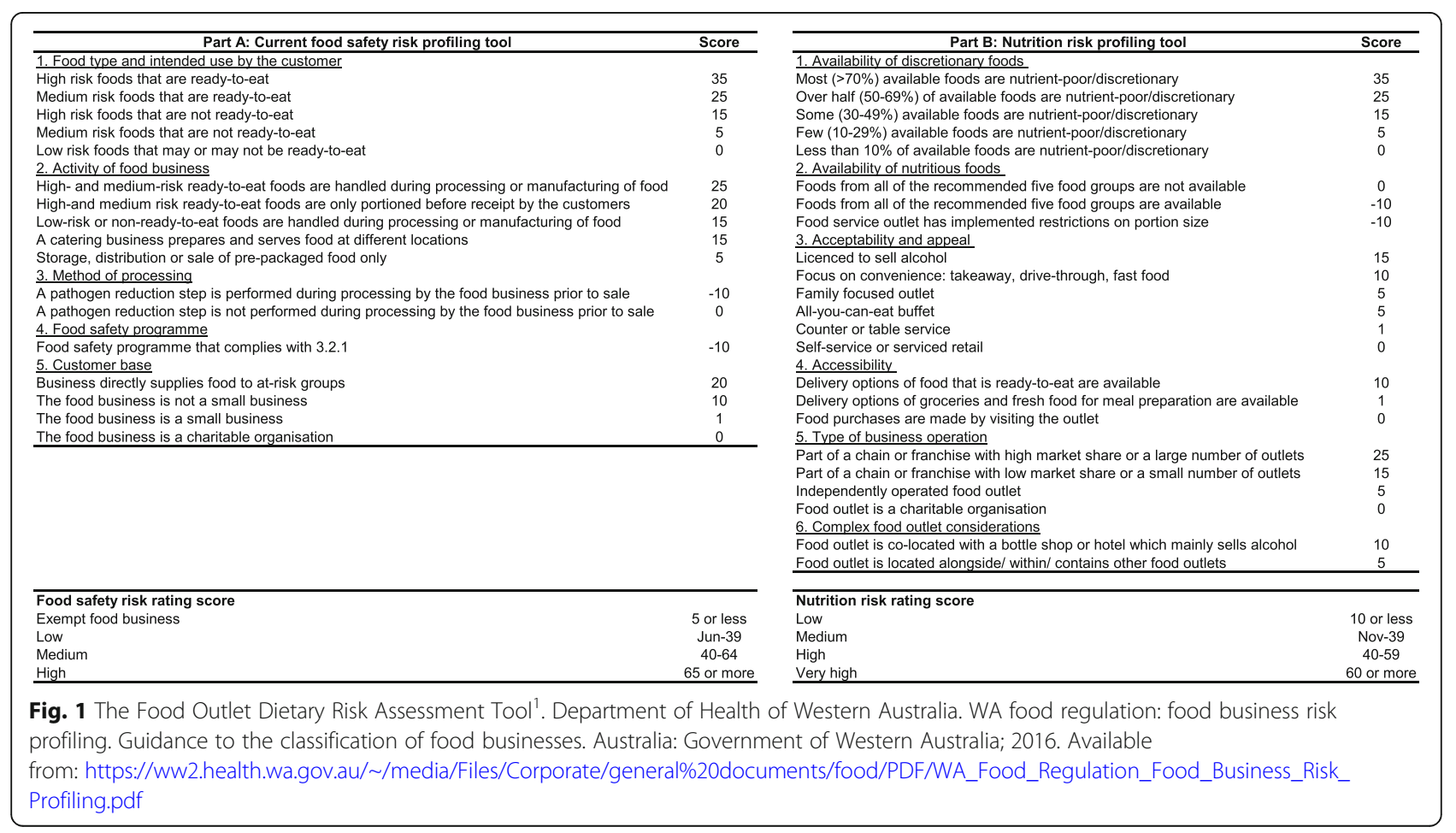


which is offset by the availability of foods from all five food groups (Fig. 1). To reflect the importance of appropriate serving sizes on the amount of food consumed, portion control in food service outlets is also included as an offset to the risk score (Fig. 1). To inform the risk assessment related to availability of healthy and unhealthy food, a literature review was conducted and is summarised in Supplementary Table 3.

\section{Other risks identified}

The acceptability, appeal, and accessibility [40] of food outlets which sell discretionary foods further impact the likelihood and severity of poor nutritional quality population diets.

The acceptability or appeal of food outlets can be influenced by making foods more convenient for consumers. For example, licenced food outlets make it easy for diners to consume alcohol. Food outlets with a drive-through takeaway service provide consumers the convenience of ordering and collecting food without leaving their car. A food outlet that provides playgrounds, toys, or special children's menus, aims to appeal to families with young children by making the experience enjoyable for the whole family. Food outlets with all-you-can-eat buffets can appeal to the budget conscious but encourage over eating. The FODR assessment tool rates the risk associated with the acceptability and appeal of food outlets, using inputs from information obtained from the internet or audits of food outlets (Fig. 1).

The risk attributable to accessibility considers the likelihood of impulse purchases, which are unplanned purchases. There is a risk associated with ordering ready-to-eat foods online or by telephone as purchase decisions can be impulsive; and unplanned purchases are often triggered by a desire to indulge [44]. Purchasing supermarket groceries online can also lead to less healthy choices [45], and marketing strategies including altering the order in which products are displayed can influence purchase decisions $[46,47]$. The FODR assessment tool rates the risk associated with online and telephone ordering using inputs from information obtained from the internet or audits of food outlets (Fig. 1).

The risk attributable to exposure is assessed by rating the type of food business operation. Food outlets that are part of a chain or franchise typically have a stronger market position, and are likely to have greater exposure to the population. This exposure can be due to the visibility gained by establishing a large number of outlets, or via investing in advertising and promotion to build brand awareness and influence consumer food choices [48]. To rate this risk, market share of the food outlet was estimated using market reports, such as the IBISWorld series [26, 49-54] (see Supplementary Table 4).

The final risk that is incorporated into the FODR assessment tool focuses on the increase in impact achieved by co-locating food outlets within one area to increase overall appeal. For example, Australian food courts have a large number of food service outlets co-located around a shared seating area and are often found in indoor shopping centres. Some supermarkets are co-located with an off-premises alcohol retailer, and increased availability and accessibility of alcohol outlets can lead to greater acceptance of alcohol and increased consumption [55]. Inputs to the FODR assessment tool are from information obtained from the internet or audits of food outlets.

\section{FODR assessment tool scoring system}

The FODR assessment tool's scoring system allocates more points to factors that pose a greater risk to public health nutrition, and food outlets are classified as having low, medium, high or very high risks depending on the overall score achieved. Development of the scoring system took into consideration the public health goal of improving the impact of food outlets on community food environments, signalling ways food outlets can improve their score. The scoring system allocates the most points to food outlets where most available foods are discretionary; therefore a food outlet could reduce their risk score by introducing more recommended nutritious foods and reducing the proportion of discretionary foods. Chains or franchises with a dominant market position are also scored a high number of points, which reflects their level of influence over food selection.

\section{Pilot testing}

To evaluate the utility and acceptability of the FODR assessment tool, food outlet data provided by one of the 13 LGAs within the EMHS area will be pilot tested by the authors. A database will be created that guides the data entry process, with prepopulated fields of data where appropriate (for example the availability of discretionary and nutritious foods in supermarkets). The ability to source data and the practical effort required will be assessed. The scores generated by the FODR assessment tool for all food outlets present in the selected community food environment will be spatially mapped using Geographical Information System (GIS) technology. Statistical analysis will be conducted including: an average risk assessment score, number of food outlets scoring high or very high public health nutrition risks, and kernel density analysis of all food outlets (which estimates the density of referenced points rather than the proximity). Interested and affected groups, including 
LGA environmental health officers and public health practitioners, will be consulted and further analyses identified during the consultations will be incorporated into the pilot testing phase. Results from pilot testing, and input received during consultations, will inform future iterations of the FODR assessment tool. Validation of the risk rating scores will be conducted, to identify whether the scores allocated by the FODR tool accurately indicate the community exposure to public health nutrition risk.

\section{Discussion}

The aim of this protocol was to describe development of a food outlets risk assessment tool which can be used to rate their public health nutrition impact. The FODR assessment tool was developed to assist LGAs within the EMHS area to identify food outlets that have a high or very risk to public health nutrition, by replicating the approach recommended by the WA Department of Health for food safety risk assessment. The risk is rated by inputting data to the tool, to provide an objective assessment of the food outlet's impact on food safety (part A) and public health nutrition (part B). The tool is suitable for use throughout Australia, and could also be adapted for use in other countries.

The FODR assessment tool requires robust data for six public health nutrition attributes for each food outlet: 1) availability of discretionary foods; 2) availability of nutritious food; 3) acceptability and appeal; 4) accessibility; 5) type of business operation; and 6) complex food outlet considerations. For food safety risk assessment, data is usually obtained during the new business registration process with LGAs, and environmental health officer assessments of food outlets. Additional data related to rating the public health nutrition risk could also be collected during these processes, including whether the food outlet is licensed to sell alcohol, offers a takeaway or drive-through service, provides children's toys or a play area, provides an all-you-can-eat buffet, delivers foods (including via a delivery service such as Uber Eats), or is co-located with a bottle shop or within a food court. Routine LGA data collected from registered food businesses could also capture whether the food outlet is independently operated or part of a franchise or chain, and details of the parent company. However, classification of available foods according to the recommendations of the Australian Dietary Guidelines requires nutrition or dietetics expertise, and it is not practical to advise environmental health officers to assess all products in each food outlet to determine the proportions of discretionary and nutritious foods. Published peerreviewed surveys which describe the availability of discretionary and nutritious foods in different types of food outlets can be used instead, where available. For example, an audit of Australian supermarket packaged foods (not fresh foods) found that half were classified as discretionary [16], which can be applied to the risk assessment of all supermarkets.

An alternative but more time-intensive method to determine availability of discretionary and nutritious foods is to conduct audits of the food outlets using a validated tool such as the Nutrition Environment Measures Survey for supermarkets or restaurants (NEMS-S and NEMS-R $[56,57])$ which were developed to assess the healthfulness of food outlets in the US and have also been used in Australia [58, 59], Brazil [60], Malta [61] and Canada [62]. The NEMS scores the availability, price and quality of a small number of healthier and less healthy foods, selected on the basis of their importance to population diets. To assist with completing the dietary risk assessment, a similar measurement tool could be developed to indicate the availability of discretionary foods and nutritious foods, for use by LGA environmental health officers during routine food business assessments. It is important to note that validation studies will be needed to ensure any new tools developed are credible, reliable and fit-for-purpose.

Frequency of food outlet assessment of dietary risk can be pragmatically guided by established processes for monitoring food safety risk by local government environmental health officers. In WA, the Department of Health recommends an approach which considers the risk profile of each food business (refer to Fig. 1, Part A). The frequency of food safety audit is guided by the risk rating score, with targets of assessing high risk food businesses every 3-12 months, medium risk food businesses every 6-18 months, and low risk food businesses every $12-24$ months [34].

To improve the healthfulness of community food environments, LGAs will need to develop appropriate policies and interventions based on the dietary risk assessment of food outlets. In WA, the requirements of the Public Health Act provide a legal mechanism for encouraging action by LGAs. The FODR tool could be used to establish baseline scores for all food outlets in an LGA's geographic area, with actions to improve ratings provided in public health plans. The 'Nourishing' framework of food policies to promote healthy diets and reduce non-communicable diseases recommends setting incentives and rules to create healthy food environments, for example setting limits on the number of fast food or takeaway outlets allowed near schools [63]. However, only 15 UK LGAs and one US city have registered the action they've taken to restrict unhealthy food outlets with the Nourishing database [64]. A recent review identified that $17 \%$ of surveyed UK LGAs had implemented health focused planning restrictions to limit hot food takeaways including: setting exclusion zones 
around schools, parks, sports centres, and youth clubs; restricting opening hours during school lunch breaks and immediately after school; setting limits to the density of takeaway food outlets permitted in retail areas; setting community infrastructure levies with funds raised being used for obesity prevention; mandating participation in healthy catering schemes; and requiring health impact assessments to accompany planning applications for new takeaways [65]. In addition, a third of surveyed UK LGAs had implemented planning restrictions on takeaway food outlets for reasons related to protecting the character of the area, which could also have positive health impacts [65]. To assist LGAs to implement action to address childhood obesity, the UK government has implemented a 'trailblazer' programme which provides funding and expert support to five projects, including a healthier retail programme which offers incentives, such as business support and subsidised advertising on LGAowned properties, for food outlets that provide more healthy foods [66]. These actions provide a good starting point for LGAs in the EMHS area to consider.

\section{Strengths and limitations}

This FODR assessment tool protocol is the first to rate the risk of food outlets to public health nutrition using objectively derived data, to the authors knowledge. Use of the FODR tool will assist in ensuring categorisation of dietary risk of specific food outlets is based on transparent and consistent criteria. In addition, the FODR assessment tool replicates the approach recommended by food regulators for risk assessment of food safety. There are limitations to its current use, which requires food outlet data to be collected for six public health nutrition attributes. Some of this data can be sourced using information obtained from the internet, including the food outlet websites and photographs posted to the Google search engine. The authors have provided two supplementary tables which include a summary of the literature describing public health nutrition impacts of food outlets (Supplementary Table 3) and Australian market data including details of major companies and their market share (Supplementary Table 4) which can also assist. Specific assessment of inappropriate marketing techniques such as making unhealthy foods appealing to children has not been factored into the FODR assessment. The ability of the FODR tool to incorporate the risk associated with on-site marketing will be assessed during pilot testing. Results from pilot testing and consultations with environmental health officers will inform future iterations of the FODR assessment tool, to ensure it provides a practical way of objectively evaluating the risk of food outlets to population diets.

\section{Conclusion}

This protocol describes development of a food outlet risk assessment tool that incorporates six public health nutrition attributes. The risk assessment approach applied in this tool aims to assist LGAs to identify the healthfulness of food outlets and their potential impact on community food environments, and is the first to do so using objectively derived data. Although it was developed to assist the 13 LGAs within the EMHS area in Perth WA, the tool can also be applied throughout Australia and adapted for use in other countries. LGAs and public health practitioners will be able to use the FODR assessment tool to assist with making planning decisions, and to inform policies and interventions to improve the healthfulness of community food environments.

\section{Supplementary Information}

The online version contains supplementary material available at https://doi. org/10.1186/s12937-020-00641-w.

Additional file 1: Supplementary Table 1. Completed SPIRIT 2013 Checklist: Recommended items to address in a clinical trial protocol and related documents*.

Additional file 2: Supplementary Table 2. Food business classification framework.

Additional file 3: Supplementary Table 3. Summary of public health nutrition impacts of consumer-facing food outlets.

Additional file 4: Supplementary Table 4. Market data to inform the public health nutrition risk rating tool for food outlets.

\section{Abbreviations \\ EMHS: East Metropolitan Health Service (in Perth, Western Australia); FODR: Food Outlet Dietary Risk assessment tool; FSANZ: Food Standards Australia New Zealand; LGA: Local government authority; mRFEl: Modified Retail Food Environment Index; NEMS-R: Nutrition Environment Measures Survey for restaurants; NEMS-S: Nutrition Environment Measures Survey for supermarkets; UK: United Kingdom; WA: Western Australia}

\section{Acknowledgments}

Not applicable

\section{Authors' contributions}

CEP conceived the study design and research objectives in consultation with CMP, CEP developed the research questions and Food Outlet Dietary Risk assessment tool in consultation with CMP, CEP wrote the first draft of the article. All authors reviewed and edited the manuscript. The author(s) read and approved the final manuscript.

\section{Funding}

G.S.A.T. is supported by a NHMRC Early Career Research Fellowship (No. 1073233). The funders had no role in study design, data collection and analysis, decision to publish, or preparation of the manuscript.

Availability of data and materials

The Food Outlet Dietary Risk Assessment Tool is provided in Fig. 1.

Ethics approval and consent to participate

Not applicable.

Consent for publication

Not applicable. 


\section{Competing interests}

The authors have no perceived or actual competing interests to declare.

\section{Author details}

'School of Public Health, Curtin University, Kent Street, GPO Box U1987, Perth, Western Australia 6845, Australia. ${ }^{2}$ East Metropolitan Health Service, Kirkman House, 20 Murray Street, East Perth, Perth, Western Australia 6004, Australia. ${ }^{3}$ Telethon Kids Institute, The University of Western Australia, PO Box 855, West Perth, Western Australia 6872, Australia. ${ }^{4}$ School of Population and Global Health, The University of Western Australia, 35 Stirling Highway, Crawley, Western Australia 6009, Australia. ${ }^{5}$ Department of Health of Western Australia, Perth, Western Australia 6004, Australia.

Received: 18 June 2020 Accepted: 2 November 2020

Published online: 12 November 2020

\section{References}

1. World Health Organization. Using price policies to promote healthier diets. Copenhagen: The Regional Office for Europe of the World Health Organization; 2015. Available from: http://www.euro.who.int/_data/assets/ pdf_file/0008/273662/Using-price-policies-to-promote-healthier-diets. pdf?ua $=1$.

2. Swinburn B, Sacks G, Vandevijvere S, Kumanyika S, Lobstein T, Neal B, et al. INFORMAS (international network for food and obesity/non-communicable diseases research, monitoring and action support): overview and key principles. Obes Rev. 2013;14(S1):1-12

3. Ni Mhurchu C, Vandevijvere S, Waterlander W, Thornton LE, Kelly B, Cameron AJ, et al. Monitoring the availability of healthy and unhealthy foods and non-alcoholic beverages in community and consumer retail food environments globally. Obes Rev. 2013;14(Suppl 1):108-19.

4. Story M, Kaphingst KM, Robinson-O'Brien R, Glanz K. Creating healthy food and eating environments: policy and environmental approaches. Annu Rev Public Health. 2008:29:253-72.

5. Glanz K, Sallis JF, Saelens BE, Frank LD. Healthy nutrition environments: concepts and measures. Am J Health Promot. 2005;19(5):330-3.

6. Lake AA, Burgoine T, Greenhalgh F, Stamp E, Tyrrell R. The foodscape: classification and field validation of secondary data sources. Health Place. 2010;16(4):666-73.

7. Thornton LE, Crawford DA, Lamb KE, Ball K. Where do people purchase food? A novel approach to investigating food purchasing locations. Int J Health Geogr. 2017;16(1):9.

8. Thornton LE, Kavanagh AM. Association between fast food purchasing and the local food environment. Nutr Diab. 2012;2:e53.

9. Lake AA. Neighbourhood food environments: food choice, foodscapes and planning for health. Proc Nutr Soc. 2018:1-8.

10. Centers for Disease Control and Prevention (CDC). Census Tract Level State Maps of the Modified Retail Food Environment Index (mRFEI). Atlanta: Department of Health and Human Services; 2011. Available from: https:// www.cdc.gov/obesity/downloads/census-tract-level-state-maps-mrfei_TAG5 08.pdf.

11. Cobb LK, Appel LJ, Franco M, Jones-Smith JC, Nur A, Anderson CAM. The relationship of the local food environment with obesity: a systematic review of methods, study quality, and results. Obesity. 2015;23(7):1331-44.

12. Caspi CE, Sorensen G, Subramanian SV, Kawachi I. The local food environment and diet: a systematic review. Health Place. 2012;18(5):1172-87.

13. McGuirt J, Jilcott Pitts $\mathrm{S}$, Gustafson A. Association between spatial access to food outlets, frequency of grocery shopping, and objectively-assessed and self-reported fruit and vegetable consumption. Nutrients. 2018;10(12):1974.

14. Pulker CE, Trapp GSA, Scott JA, Pollard CM. Global supermarkets' corporate social responsibility commitments to public health: a content analysis. Glob Health. 2018;14(1):121.

15. Cloutman N. Supermarkets and grocery stores in Australia. IBISWorld industry report G4111. Australia: IBIS World; 2017. Available from: http:// clients1.ibisworld.com.au.dbgw.lis.curtin.edu.au/reports/au/industry/default. aspx?entid=1834.

16. Ni Mhurchu C, Brown R, Jiang Y, Eyles H, Dunford E, Neal B. Nutrient profile of 23596 packaged supermarket foods and non-alcoholic beverages in Australia and New Zealand. Public Health Nutr. 2016;19(3):401-8.

17. Dixon H, Scully M, Parkinson K. Pester power: snackfoods displayed at supermarket checkouts in Melbourne, Australia. Health Promot J Aust. 2006; 17(2):124-7.
18. Thornton LE, Cameron AJ, McNaughton SA, Waterlander WE, Sodergren M, Svastisalee $C$, et al. Does the availability of snack foods in supermarkets vary internationally? Int J Behav Nutr Phys Act. 2013;10:56.

19. Thornton LE, Cameron AJ, McNaughton SA, Worsley A, Crawford DA. The availability of snack food displays that may trigger impulse purchases in Melbourne supermarkets. BMC Public Health. 2012;12:194.

20. Lucio R. Woolies now holds over 50 per cent of all alcohol sales Australia: Inside FMCG; 2018 [Available from: https://insidefmcg.com.au/2018/06/25/ woolies-now-holds-over-50-per-cent-of-all-alcohol-sales/\#daily.

21. Stern D, Poti JM, Ng SW, Robinson WR, Gordon-Larsen P, Popkin BM. Where people shop is not associated with the nutrient quality of packaged foods for any racial-ethnic group in the United States. Am J Clin Nutr. 2016;103(4): $1125-34$.

22. Pulker CE, Trapp GSA, Scott JA, Pollard CM. What are the position and power of supermarkets in the Australian food system, and the implications for public health? A systematic scoping review. Obes Rev. 2018;19(2):198-218.

23. Guthrie JF, Lin B-H, Frazao E. Role of food prepared away from home in the American diet, 1977-78 versus 1994-96: changes and consequences. J Nutr Educ Behav. 2002;34(3):140-50.

24. Clifford Astbury C, Penney TL, Adams J. Home-prepared food, dietary quality and socio-demographic factors: a cross-sectional analysis of the UK National Diet and nutrition survey 2008-16. Int J Behav Nutr Phys Act. 2019;16(1):82.

25. Anaf J, Baum FE, Fisher M, Harris E, Friel S. Assessing the health impact of transnational corporations: a case study on McDonald's Australia. Glob Health. 2017;13(1):7.

26. Magner L. Fast food services in Australia. IBISWorld industry report H4512. Australia: IBIS World; 2017.

27. Innes-Hughes C, Boylan S, King LA, Lobb E. Measuring the food environment in three rural towns in New South Wales, Australia. Health Promot J Aust. 2012;23(2):129-33.

28. Miura K, Giskes K, Turrell G. Socioeconomic differences in takeaway food consumption and their contribution to inequalities in dietary intakes. J Epidemiol Community Health. 2009;63(10):820.

29. Moayyed H, Kelly B, Feng X, Flood V. Evaluation of a 'healthiness' rating system for food outlet types in Australian residential communities. Nutr Diet. 2017;74(1):29-35.

30. Codex Alimenatarius Commission. Procedural Manual: Section III Working Principles for Risk Analysis for Application in the Framework of the Codex Alimentarius Rome. Rome: Food and Agriculture Organization of the United Nations and World Health Organization; 2003. Available from: http://www. fao.org/3/a0247e/a0247e04.htm\#bm04.1.

31. Codex Alimenatarius Commission. Understanding Codex Rome. Rome: Food and Agriculture Organization of the United Nations and World Health Organization; 2018. Available from: http://www.fao.org/3/ca1176en/CA1176EN.pdf.

32. Food Standards Australia New Zealand. Risk analysis in food regulation. Australia: FSANZ; 2013. Available from: http://www.foodstandards.gov.au/ publications/riskanalysisfoodregulation/Pages/default.aspx.

33. Lawrence MA, Pollard CM, Weeramanthri TS. Positioning food standards programmes to protect public health: current performance, future opportunities and necessary reforms. Public Health Nutr. 2019;22(5):912-26.

34. Department of Health of Western Australia. WA food regulation: food business risk profiling. Guidance to the classification of food businesses. Australia: Government of Western Australia; 2016. Available from: https:// ww2.health.wa.gov.au/ /media/Files/Corporate/general\%20documents/ food/PDF/WA_Food_Regulation_Food_Business_Risk_Profiling.pdf.

35. Department of Health of Western Australia. Public health act 2016 handbook. Australia: Government of Western Australia; 2017. Available from: https://ww2.health.wa.gov.au/ /media/Files/Corporate/general\%2 Odocuments/Public\%20Health\%20Act/Handbook/PHA-Handbook-for-LG.pdf.

36. Public Health Association of Australia. A future for food. Healthy, sustainable, fair. Australia: PHAA; 2012. Available from: https://www.phaa.net.au/ documents/item $/ 562$.

37. Department of Health of Western Australia. East Metropolitan Health Service Australia. Perth: Government of Western Australia; 2019. Available from: https://ww2.health.wa.gov.au/About-us/East-Metropolitan-Health-Service.

38. Chan A, Tetzlaff JM, Altman DG, et al. Spirit 2013 statement: defining standard protocol items for clinical trials. Ann Intern Med. 2013;158(3):200-7.

39. National Health and Medical Research Council. Eat for health. Educator guide. Canberra: Commonwealth of Australia; 2013. Available from: https:/ www.eatforhealth.gov.au/sites/default/files/files/the_guidelines/n55b_ educator_guide_140321.pdf. 
40. National Health and Medical Research Council. Australian Dietary Guidelines. Canberra: Commonwealth of Australia; 2013. Available from: http://www. eatforhealth.gov.au/sites/default/files/files/the_guidelines/n55_australian_ dietary_guidelines.pdf. Archived at http://www.webcitation.org/6WtXXmGt4.

41. Australian Bureau of Statistics. National Health Survey: First results, 2017-18, cat.no. 4364.0.55.001. Canberra: Australian Bureau of Statistics; 2018. Available from: https://www.abs.gov.au/AUSSTATS/abs@.nsf/Lookup/4364. 0.55.001Main+Features702017-18?OpenDocument.

42. Australian Bureau of Statistics. Australian Health Survey: Consumption of food groups from the Australian Dietary Guidelines, 2011-12, cat. no. 4364. 0.55.012. Canberra: Australian Bureau of Statistics; 2016. Available from: http://www.abs.gov.au/ausstats/abs@.nsf/Lookup/by\%20Subject/4364.0.55. 012 2011-12 Main\%20Features Key\%20Findings 1.

43. Afshin A, Sur PJ, Fay KA, Cornaby L, Ferrara G, Salama JS, et al. Health effects of dietary risks in 195 countries, 1990-2017: a systematic analysis for the Global Burden of Disease Study 2017. Lancet. 2019;393(10184):1958-72.

44. Kalla SM, Arora AP. Impulse buying: a literature review. Glob Bus Rev. 2011; 12(1):145-57.

45. Jilcott Pitts SB, Ng SW, Blitstein JL, Gustafson A, Niculescu M. Online grocery shopping: promise and pitfalls for healthier food and beverage purchases. Public Health Nutr. 2018:1-17.

46. Koutoukidis DA, Jebb SA, Ordóñez-Mena JM, Noreik M, Tsiountsioura M, Kennedy $\mathrm{S}$, et al. Prominent positioning and food swaps are effective interventions to reduce the saturated fat content of the shopping basket in an experimental online supermarket: a randomized controlled trial. Int J Behav Nutr Phys Act. 2019;16(1):50.

47. Danciu V. Manipulative marketing: persuasion and manipulation of the consumer through advertising. Theor Appl Econ. 2014;18(2 (591)):19-34.

48. Boyland EJ, Whalen R. Food advertising to children and its effects on diet: review of recent prevalence and impact data. Pediatr Diabetes. 2015;16(5): 331-7.

49. Vuong B. Cafes and coffee shops in Australia. IBISWorld industry report H4511b. Australia: IBIS World; 2017. Available from: http://clients1.ibisworld. com.au.dbgw.lis.curtin.edu.au/reports/au/industry/default.aspx?entid=2015.

50. Magner L. Fast food burger shops in Australia. IBISWorld industry report OD5498. Australia: IBISWorld; 2017. Available from: http://clients1.ibisworld. com.au.dbgw.lis.curtin.edu.au/reports/au/industry/default.aspx?entid=5498.

51. Vuong B. Fish and chip shops in Australia. IBISWorld industry report OD5499. IBISWorld: Australia; 2017. Available from: http://clients1.ibisworld. com.au.dbgw.lis.curtin.edu.au/reports/au/industry/default.aspx?entid=5499.

52. Vuong B. Pizza restaurants and takeaway in Australia. IBISWorld industry report OD4025. Australia: IBISWorld; 2017. Available from: http://clients1. ibisworld.com.au.dbgw.lis.curtin.edu.au/reports/au/industry/default. aspx?entid=4025.

53. Johnson S. Takeaway chicken shops in Australia. IBISWorld industry report OD5500. Australia: IBISWorld; 2017. Available from: http://clients1.ibisworld. com.au.dbgw.lis.curtin.edu.au/reports/au/industry/default.aspx?entid=5500.

54. McGregor W. Pubs, bars and nightclubs in Australia. IBISWorld industry report H4520. Australia: IBISWorld; 2017. Available from: http://clients1. ibisworld.com.au.dbgw.lis.curtin.edu.au/reports/au/industry/default. aspx?entid $=448$.

55. Foster S, Hooper P, Knuiman M, Trapp G, Wood L. Does alcohol outlet density differ by area-level disadvantage in metropolitan Perth? Drug Alcohol Rev. 2017;36(5):701-8.

56. Glanz K, Sallis JF, Saelens BE, Frank LD. Nutrition environment measures survey in stores (NEMS-S): development and evaluation. Am J Prev Med. 2007:32(4):282-9.

57. Saelens BE, Glanz K, Sallis JF, Frank LD. Nutrition environment measures study in restaurants (NEMS-R): development and evaluation. Am J Prev Med. 2007;32(4):273-81.

58. Carins J, Rundle-Thiele S. Fighting to eat healthfully: measurements of the military food environment. J Soc Mark. 2014;4(3):223-39.

59. Carins JE, Rundle-Thiele S, Storr RJ. Appraisal of short and long versions of the nutrition environment measures survey (NEMS-S and NEMS-R) in Australia. Public Health Nutr. 2018:1-7.

60. Martins PA, Cremm EC, Leite FHM, Maron LR, Scagliusi FB, Oliveira MA Validation of an adapted version of the nutrition environment measurement tool for stores (NEMS-S) in an urban area of Brazil. J Nutr Educ Behav. 2013;45(6):785-92.

61. Cauchi D, Pliakas T, Knai C. Food environments in Malta: associations with store size and area-level deprivation. Food Policy. 2017;71:39-47.
62. Lo BK, Minaker LM, Mah CL, Cook B. Development and Testing of the Toronto Nutrition Environment Measures Survey-Store (ToNEMS-S). J Nutr Educ Behav. 2016;48(10):723-9 e1.

63. Hawkes C, Jewell J, Allen K. A food policy package for healthy diets and the prevention of obesity and diet-related non-communicable diseases: the NOURISHING framework. Obes Rev. 2013;14:159-68.

64. World Cancer Research Fund International. NOURISHING framework - Set incentives and rules to create a healthy retail and food service environment. London: World Cancer Research Fund International; 2019. Available from: https://www.wcrf.org/sites/default/files/6_Set\%20Incentives_May2019.pdf.

65. Keeble M, Burgoine T, White M, Summerbell C, Cummins S, Adams J. How does local government use the planning system to regulate hot food takeaway outlets? A census of current practice in England using document review. Health Place. 2019;57:171-8.

66. Local Government Association. Childhood Obesity Trailblazer Programme UK. London: Local Government Association; 2019. Available from: https:// www.local.gov.uk/childhood-obesity-trailblazer-programme.

\section{Publisher's Note}

Springer Nature remains neutral with regard to jurisdictional claims in published maps and institutional affiliations.

\section{Ready to submit your research? Choose BMC and benefit from:}

- fast, convenient online submission

- thorough peer review by experienced researchers in your field

- rapid publication on acceptance

- support for research data, including large and complex data types

- gold Open Access which fosters wider collaboration and increased citations

- maximum visibility for your research: over $100 \mathrm{M}$ website views per year

At BMC, research is always in progress.

Learn more biomedcentral.com/submissions 